\title{
Serum Cystatin C Assay
}

National Cancer Institute

\section{Source}

National Cancer Institute. Serum Cystatin C Assay. NCI Thesaurus. Code C88224.

An immunoassay used for the measurement of cystatin-C levels in the serum to determine the glomerular filtration rate. 